\title{
A Simple and Inexpensive Option in Nonsurgical Splenic Artery Aneurysm Treatment by Coronary Bare Metal Stents
}

\author{
Fatih Yilmaz, Ali Karagoz, Gonenc Kocabay \\ Department of Cardiology, Kartal Kosuyolu Heart and Research Hospital, Istanbul, Turkey \\ ORCID: \\ Fatih Yilmaz: https://orcid.org/0000-0002-3006-1942 \\ Ali Karagoz: https://orcid.org/0000-0002-0438-2021 \\ Gonenc Kocabay: https://orcid.org/0000 000214390252
}

\section{Abstract}

Visceral artery aneurysms can be life-threatening conditions with a high incidence of rupture. The endovascular technique with coil embolization is successful procedure for aneurysm treatment. Herein, we presented a case with a new and inexpensive treatment of splenic artery aneurysm by a coronary bare metal stent.

Keywords: Coronary bare metal stents, splenic artery aneurysm, treatment

\section{INTRODUCTION}

Visceral artery aneurysms and pseudoaneurysms can be life-threatening conditions with a high incidence of rupture. Absolute risk factors for splenic artery aneurysms (SAA) are not known, and possible risk factors for true and pseudoaneurysms vary. True SAAs are more frequent than pseudo-SAAs; the main risk factors for true SAAs are hypertension, atherosclerosis, cirrhosis, portal hypertension, liver transplantation, collagen tissue diseases female sex, pregnancy, and multiparity ${ }^{[1]}$ More than $70 \%$ of SAA cases are symptom-free and incidentally detected in radiological assessments performed for diverse medical conditions. They are most commonly seen in patients in their $50 \mathrm{~s}$ and $60 \mathrm{~s}$ and show a woman dominance. The most common pain or discomfort in the epigastric and left upper quadrants. SAA care can vary depending on the age, gender, dimension of the aneurysm, location, abnormalities, and extent of clinical findings. For the treatment of SAA, endovascular treatment (coil embolization or stenting) and surgery are preferred. ${ }^{[2-4]}$ The endovascular technique was successful in $98 \%$ of 48 procedures. Coil embolization was used in $96 \%$ of the cases for aneurysm treatment. There was not any death

Received: 27-06-2020 Revised: 23-08-2020 Accepted: 20-10-2020

Published Online: 27-11-2020

\begin{tabular}{|l|l|}
\hline \multicolumn{3}{c|}{ Access this article online } \\
\hline Quick Response Code: & Website: \\
& \\
http://www.ijcva.com
\end{tabular}

in those who underwent elective intervention. ${ }^{[2]}$ The aim of this report is to present a case with a new and inexpensive treatment of splenic artery aneurysm by a coronary bare-metal stent (BMS).

\section{Case Report}

A 22-year-old female patient with progressive left upper quadrant pain for 3 months referred to our clinic from a general surgery clinic because of the splenic aneurysm which was detected by abdomen ultrasonography. On physical examination, her blood pressure was 119/82 $\mathrm{mm} \mathrm{Hg}$, and her pulse was 72 beats $/ \mathrm{min}$. The patient was not under any medical treatment and had no history of trauma or surgery. There was no history of any systemic infection, pregnancy, family history of aneurysm, and connective tissue disorder. Abdominal ultrasonography revealed that splenic artery diameter reaches $21 \mathrm{~mm}$. Because of the desire of pregnancy, we decided to proceed with intervention for SAA. We planned to implant

Address for correspondence: Gonenc Kocabay, MD, Department of Cardiology, Kartal Kosuyolu Heart and Research Hospital, Istanbul, Turkey. E-mail: gonenckocabay@yahoo.com

This is an open access journal, and articles are distributed under the terms of the Creative Commons Attribution-NonCommercial-ShareAlike 4.0 License, which allows others to remix, tweak, and build upon the work non-commercially, as long as appropriate credit is given and the new creations are licensed under the identical terms.

For reprints contact: WKHLRPMedknow_reprints@wolterskluwer.com

How to cite this article: Yilmaz F, Karagoz A, Kocabay G. A simple and inexpensive option in nonsurgical splenic artery aneurysm treatment by coronary bare metal stents. Int J Cardiovasc Acad 2020;6:186-8. 
splenic artery coil embolization because the patient refused surgery, who was scheduled for coil embolization.

Stent-graft implantation was not possible due to the tortuosity of the splenic artery. Coil embolization was possible for wide aneurysm; however, due to the lack of economic infrastructure we were not able to do this procedure. We eventually decided to close the feeding artery with BMS and we also planned to put BMS into an aneurysm sac with low pressure to create a tendency to thrombosis process.

Because of the first splenic angiogram procedure was not appropriate for wire insertion and lack of coaxiality of the catheter to the splenic artery by the femoral approach we decided to perform a stent implantation procedure from the brachial artery approach [Figures 1 and 2]. The splenic artery was passed through with a soft 0.014 -inch workhorse guidewire (Asahi SION JP). A splenic angiogram was obtained again and reference values of the feeding artery were recorded by contrast injection. We released three BMS $4.0 \mathrm{~mm} \times 20$ $\mathrm{mm}$ (Commander ${ }^{\mathrm{TM}} \mathrm{CoCr}$ Alvimedica) at $4 \mathrm{~atm}$ pressure put into aneurysm sac in a different part of it [Figures 3-5] (feeding artery isolation). We choose the larger size stent to prevent it from being embolized to the distal splenic artery.

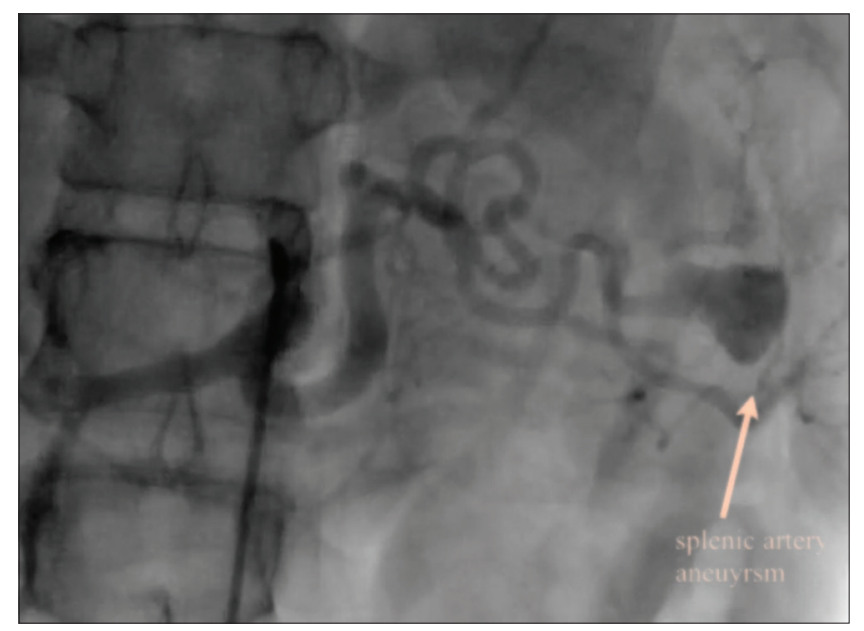

Figure 1: Celiac angiography by the femoral approach

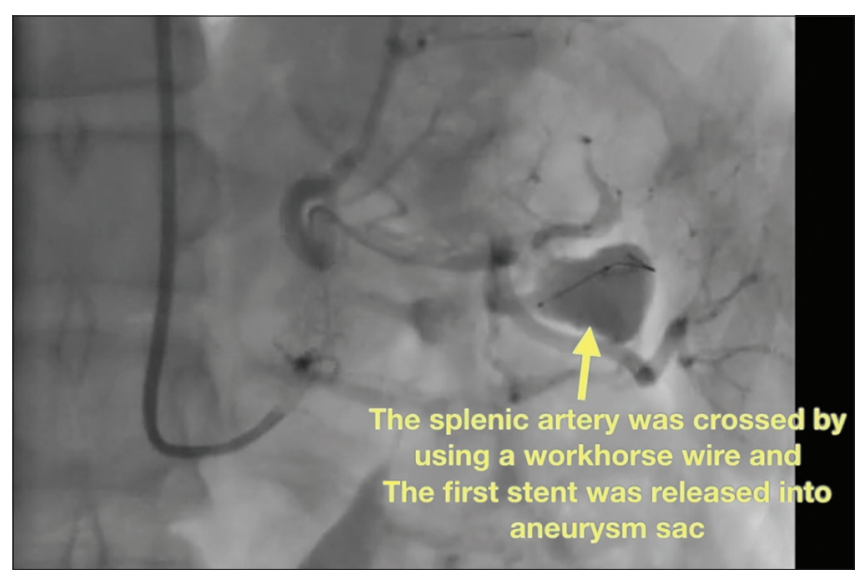

Figure 3: Releasing of the first bare-metal stent into aneurysm sac
Another $3.5 \mathrm{~mm} \times 20 \mathrm{~mm}$ BMS (Commander ${ }^{\mathrm{TM}} \mathrm{CoCr}$ Alvimedica) was implanted to the proximal portion of the aneurysm (feeding artery) with undersized stent size and twice prolonged balloon inflation using the stent balloon at low pressure ( $4 \mathrm{~atm}-60 \mathrm{~s})$ moreover after that at $4 \mathrm{~atm}$ pressure, procedure completed without any complication. After the completetion procedure, angiogram showed decreased flow of the aneurysm sac.

The patient was discharged two days after the procedure. At the $6^{\text {th }}$ month, computed tomography showed thrombosed aneurysm sack, aneurysm decrease to $1.8 \mathrm{~cm}$ and sac thrombosed [Figure 6]. The patient was clinically comforted without any complaint at discharge and follow-up. After the procedure, we observed an improvement in symptoms and during follow-up visits did not encounter any complication.

\section{Discussion}

The treatment of SAAs may change according to age, sex, aneurysm dimension, location, complications, and severity of the clinical findings. Clinicians should reckon the size and the

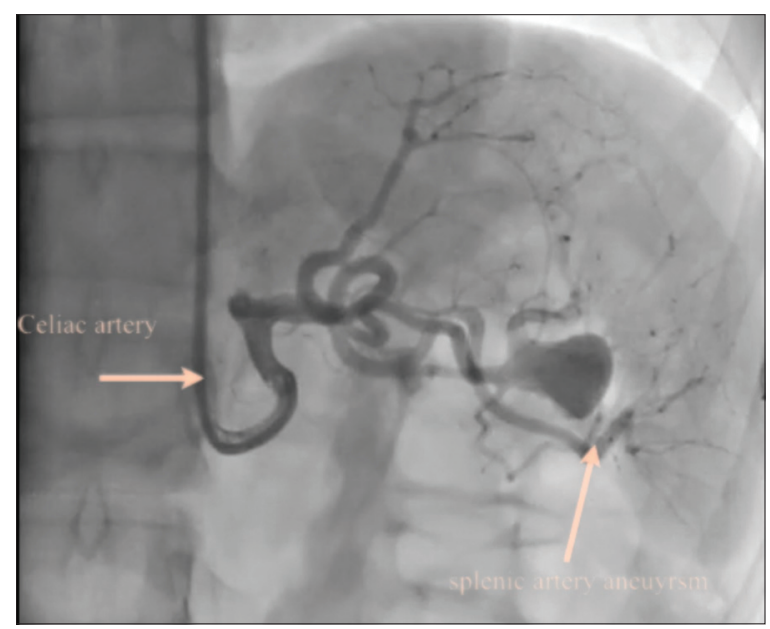

Figure 2: Selective splenic angiography by the brachial approach

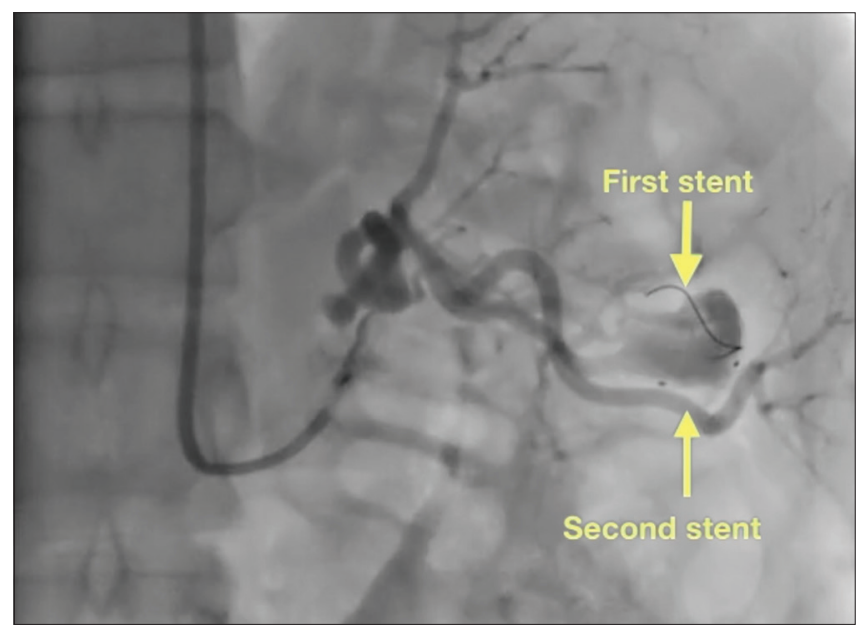

Figure 4: Releasing of the second bare metal stent into aneurysm sac 


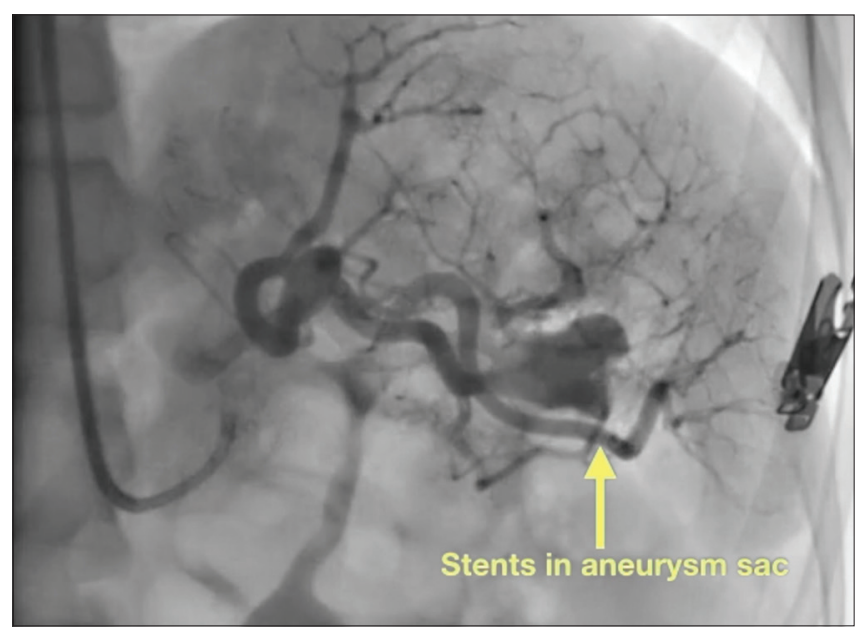

Figure 5: Decreased blood flow in aneurysm sac after three bare metal stents placement has shown

risk of rupture, which is high during pregnancy, and the relative risk of surgical or endovascular intervention when deciding to intervention. For large, symptomatic, or aneurysms with a high risk of rupture, endovascular treatment has become the first-line therapy. Endovascular treatment options are becoming more favored due to their acceptable technical success and low morbidity rates. ${ }^{[3]}$ Surgery and endovascular treatment methods such as stent-graft implantation, coil embolization, plug deployment, or glue embolization have been used for many years. The systematic review revealed metallic coils and covered stent grafts were the most commonly used embolic materials for the treatment of splenic artery aneurysm. ${ }^{[4]}$ The inflow vessels of the aneurysm were traumatized (i.e., isolation technique) and the aneurysm itself was packed with stents (i.e., packing technique). In previous studies, even if it is said that at least more than $50 \%$ of the area should be filled with coil, as in our case may have no need for this because we used repeated prolonged balloon inflation the proximal feeding artery. ${ }^{[3,4]}$

The aim of this report is to present a case with a new and inexpensive treatment of splenic artery aneurysm by a coronary BMS. We consider that this technique might be a low-cost alternative to other methods and safe in splenic artery aneurysm patients. Interventionists might perform these techniques with ease and could be life-saving. Informed consent was obtained from the patient, institutional board review approval was not required.

\section{Conclusion}

Endovascular treatment, among which transcatheter embolization is preferred, remains a treatment of choice for

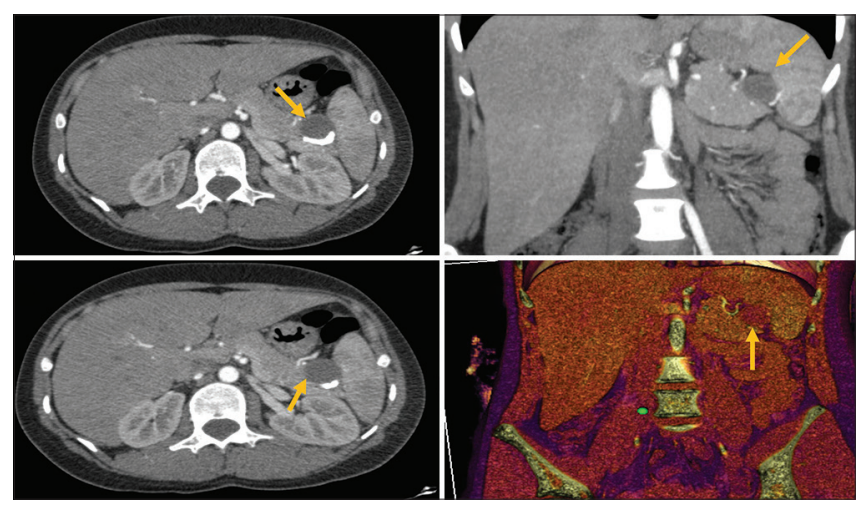

Figure 6: After six months, computed tomography angiography showed thrombosed aneurysm sack

most of the elective and acute cases of the splenic aneurysm, in these ways, patients exposure to surgical morbidity and mortality can reduce. The splenic artery might be occluded safely and inexpensively in particular cases. The use of BMS in splenic aneurysm treatment might be considered as a safe and inexpensive method between endovascular treatment choices. In this case report, we showed occlusion of splenic artery aneurysm by BMS.

\section{Declaration of patient consent}

The authors certify that they have obtained all appropriate patient consent forms. In the form the patient(s) has/have given his/her/their consent for his/her/their images and other clinical information to be reported in the journal. The patients understand that their names and initials will not be published and due efforts will be made to conceal their identity, but anonymity cannot be guaranteed.

\section{Financial support and sponsorship} Nil.

\section{Conflicts of interest}

There are no conflicts of interest.

\section{REFERENCES}

1. Venturini M, Marra P, Colarieti A, Agostini G, Lanza C, Augello L, et al. Covered stenting and transcatheter embolization of splenic artery aneurysms in diabetic patients: A review of endovascular treatment of visceral artery aneurysms in the current era. Pharmacol Res 2018;135:127-35.

2. Tulsyan N, Kashyap VS, Greenberg RK, Sarac TP, Clair DG, Pierce G, et al. The endovascular management of visceral artery aneurysms and pseudoaneurysms. J Vasc Surg 2007;45:276-83.

3. Sachdev-Ost U. Visceral artery aneurysms: Review of current management options. Mt Sinai J Med 2010;77:296-303.

4. Kok HK, Asadi H, Sheehan M, Given MF, Lee MJ. Systematic Review and Single-Center Experience for Endovascular Management of Visceral and Renal Artery Aneurysms. J Vasc Interv Radiol 2016;27:1630-41. 